\title{
Rodent Model of Muscular Atrophy for Sarcopenia Study
}

\author{
Kyung-Wan Baek ${ }^{1,3, *}$, Youn-Kwan Jung ${ }^{2, *}$, Ji-Seok Kim ${ }^{1}$, Jin Sung Park ${ }^{3}$, Young-Sool Hah², So-Jeong Kim4, \\ Jun-II Yoo ${ }^{3}$ \\ 'Department of Physical Education, Gyeongsang National University, Jinju; \\ ${ }^{2}$ Biomedical Research Institute, Gyoengsang National University Hospital, Gyeongsang National University, Jinju; \\ ${ }^{3}$ Department of Orthopaedic Surgery, Gyoengsang National University Hospital, Gyeongsang National University, Jinju; \\ ${ }^{4}$ Department of Convergence of Medical Sciences, Gyeongsang National University, Jinju, Korea
}

\section{Corresponding author \\ Jun-II Yoo \\ Department of Orthopaedic Surgery, \\ Gyeongsang National University Hospital, \\ 79 Gangnam-ro, Jinju 52727, Korea \\ Tel: +82-55-750-8688 \\ Fax: +82-55-754-0477 \\ E-mail: furim@hanmail.net}

Received: April 22, 2020

Revised: May 15, 2020

Accepted: May 16, 2020

*Kyung-Wan Baek and Youn-Kwan Jung contributed equally to this work and should be considered co-first authors.
Copyright $@ 2020$ The Korean Society for Bone and Mineral Research

This is an Open Access article distributed under the terms of the Creative Commons Attribution Non-Commercial License (https://creativecommons.org/licenses/by-nc/4.0/) which permits unrestricted non-commercial use, distribution, and reproduction in any medium, provided the original work is properly cited.

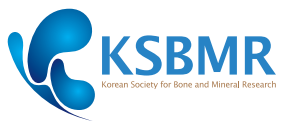

The hallmark symptom of sarcopenia is the loss of muscle mass and strength without the loss of overall body weight. Sarcopenia patients are likely to have worse clinical outcomes and higher mortality than do healthy individuals. The sarcopenia population shows an annual increase of $\sim 0.8 \%$ in the population after age 50 , and the prevalence rate is rapidly increasing with the recent worldwide aging trend. Based on International Classification of Diseases, Tenth Revision, a global classification of disease published by the World Health Organization, issued the disease code (M62.84) given to sarcopenia in 2016. Therefore, it is expected that the study of sarcopenia will be further activated based on the classification of disease codes in the aging society. Several epidemiological studies and meta-analyses have looked at the correlation between the prevalence of sarcopenia and several environmental factors. In addition, studies using cell lines and rodents have been done to understand the biological mechanism of sarcopenia. Laboratory rodent models are widely applicable in sarcopenia studies because of the advantages of time savings, cost saving, and various analytical applications that could not be used for human subjects. The rodent models that can be applied to the sarcopenia research are diverse, but a simple and fast method that can cause atrophy or aging is preferred. Therefore, we will introduce various methods of inducing muscular atrophy in rodent models to be applied to the study of sarcopenia.

Key Words: Aging · Muscular atrophy · Muscle, skeletal · Rodentia $\cdot$ Sarcopenia

\section{INTRODUCTION}

Sarcopenia is a degenerative disease in which the mass, quality, and strength of skeletal muscle are lost by aging.[1] The sarcopenia population shows an annual increase rate of $\sim 0.8 \%$ in the population after the age of 50 , and the prevalence rate is rapidly increasing with the recent worldwide aging trend.[2] Based on International Classification of Diseases, Tenth Revision, a global classification of diseases published by the World Health Organization, issued the disease code (M62.84) given to sarcopenia in 2016.[3]

Although the study of sarcopenia has been active for a long time, it is expected that such study will be further activated based on the classification of disease 
codes in the aging society. The study of sarcopenia can be largely divided into epidemiologic studies, meta-analyses, and experimental studies based on human and rodent interventions. Epidemiologic studies and meta-analyses focus on the study of the prevalence of sarcopenia and the interrelationship between environmental factors. These studies have demonstrated that muscle mass decreases with aging, which leads to physical disability,[4] and that in a highly active population, loss of muscle mass may not be as important as strength loss for predicting functional decline.[5] In experimental studies, research on the effects of exercise and dietary interventions and drug therapy on humans [6,7] and rodents has been done.[8] However, many studies have sought to understand the biological mechanism of sarcopenia based on molecular biological methods rather than on human studies. Thus, in vitro studies using cell lines and rodent studies are also being conducted.[9-11]
Because of the advantages of saving time and cost and of using various analytical applications than cannot be used in human studies, laboratory rodent models can be widely used in sarcopenia studies. However, the causes of sarcopenia are very diverse, and it is very important to select an appropriate rodent model according to the research purpose. The rodent models that can be applied to the sarcopenia research are diverse, but a simple and fast method that can cause atrophy or aging is preferred. Therefore, we will introduce various methods of inducing muscle atrophy in rodent models to be applied to the study of sarcopenia (Fig. 1).

\section{AGED-RODENT MODEL}

Aged rodents have been widely used for studying sarcopenia (Table 1). Aged-rodent models are the most natural

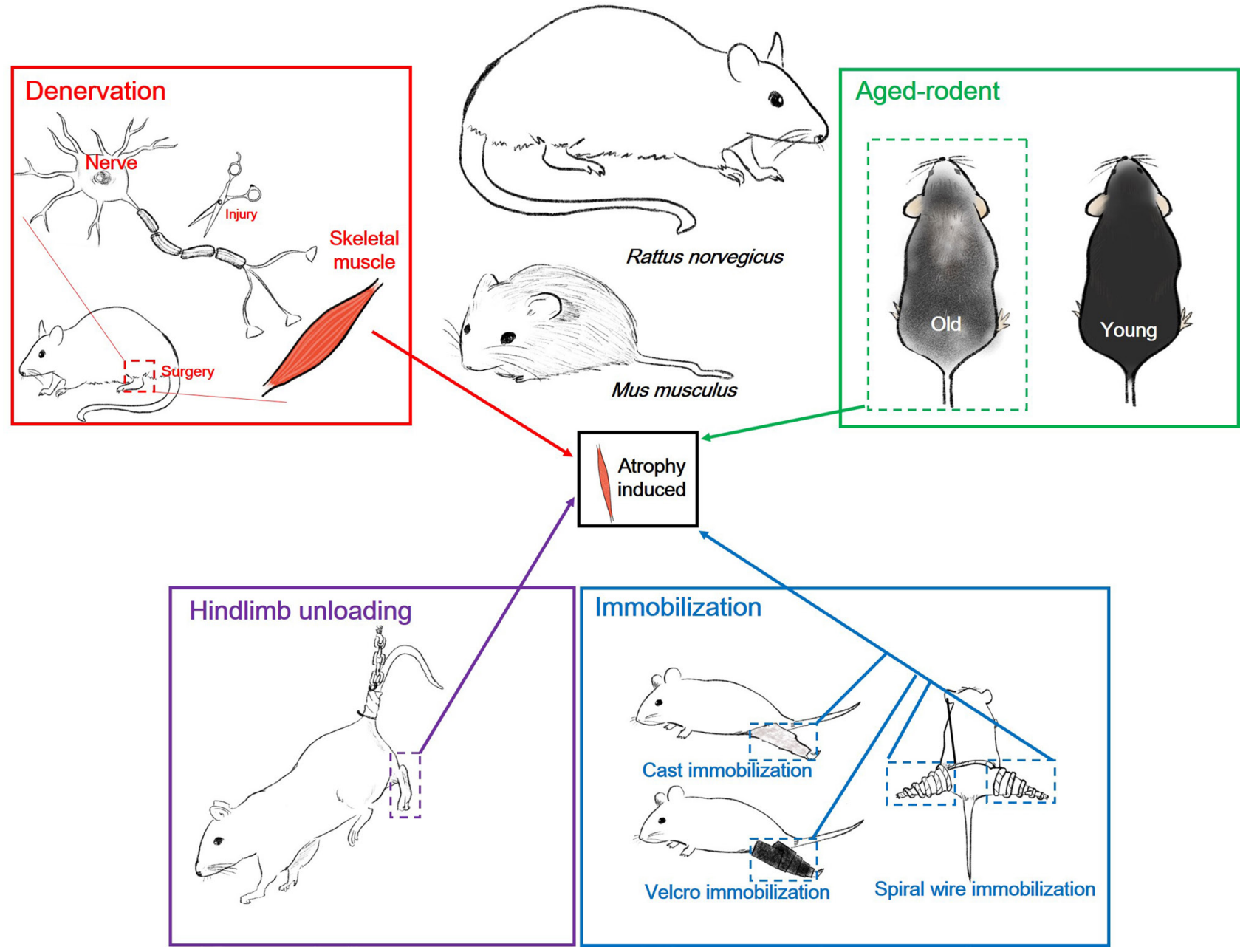

Fig. 1. Rodent model of muscular atrophy for sarcopenia study. 
Table 1. Aged-rodent models that applicable for study on sarcopenia, and key findings from individual studies

\begin{tabular}{lcccc}
\hline References & Strain & $\begin{array}{c}\text { Intervention/ } \\
\text { phenotype }\end{array}$ & $\begin{array}{c}\text { Age at sacrifice } \\
\text { (month) }\end{array}$ & Checked variable/key findings \\
\hline $\begin{array}{l}\text { Shavlakadze and Grounds [13], Chai et al. } \\
\text { [14], Schiaffino and Mammucari [15], }\end{array}$ & C57BL/6 mice & Natural aging & $24-29$ & $\begin{array}{c}\text { NMJ morphology of myofibers, lower IGF-1 in } \\
\text { aged mice, poor gait characteristics in aged } \\
\text { Tarantini et al. [17] }\end{array}$ \\
$\begin{array}{l}\text { Pötsch et al. [18] } \\
\text { mice }\end{array}$ \\
Kob et al. [21] & Wistar Han rats & Natural aging & 19 & $\begin{array}{c}\text { Decreased body weight, LBM and fat mass in } \\
\text { aged rats }\end{array}$ \\
\hline
\end{tabular}

SD, Sprague-Dawley; HFD, high-fat diet; NMJ, neuromuscular junction; IGF-1, Insulin-like growth factor-1; LBM, lean body mass.

Table 2. Hindlimb unloading rodent models that applicable for study on sarcopenia, and key findings from individual studies

\begin{tabular}{|c|c|c|c|c|}
\hline References & Strain & Intervention/phenotype & Age at sacrifice & Checked variable/key findings \\
\hline Deavers et al. [27] & SD rats & $\begin{array}{l}\text { Head-down suspension with } \\
\text { single hindlimb support }\end{array}$ & 7 days & $\begin{array}{l}\text { Lower muscle mass-to-body mass in soleus, } \\
\text { plantaris and gastrocnemius }\end{array}$ \\
\hline Halloran et al. [32] & SD rats & Tail traction with tape & 4 weeks & $\begin{array}{l}\text { Bone formation and apposition rate were low in } \\
\text { tibiofibular junctions of unloaded rats }\end{array}$ \\
\hline Fell et al. [33] & SD rats & $\begin{array}{l}\text { Whole-body suspension with } \\
\text { hindlimd-load bearing }\end{array}$ & 1 week & $\begin{array}{l}\text { Muscle atrophy significantly increases fatigability } \\
\text { in gastrocnemius }\end{array}$ \\
\hline Fitts et al. [34] & SD rats & $H S, H I$ & 2 weeks & $\begin{array}{l}\text { HS produced increases in muscle shortening. } \\
\text { HI did not differ in muscle shortening }\end{array}$ \\
\hline Jaspers and Tischler [35] & SD rats & Hindlimb tail-cast suspension & 6 days & $\begin{array}{l}\text { Six days is the optimum duration for muscle } \\
\text { unloading studies }\end{array}$ \\
\hline
\end{tabular}

SD, Sprague-Dawley; HS, hindlimb suspension; HI, hindlimb immobilization.

model and have several advantages compared to other sarcopenia models, including hindlimb unloading (HU) and disuse atrophy models. Aged rodents have morbidities and mechanisms fairly similar to those found in human sarcopenia patients, but the high cost and limited availability of aged rodents make the use of this model somewhat difficult.[12]

Female C57BL/6J mice developed sarcopenia with significant loss of quadriceps muscle mass by 24 months that was more pronounced by 27 to 29 months,[13] at a time when there is denervation and altered neuromuscular junctions (NMJ) morphology of myofibers.[14] Insulin-like growth factor-1 (IGF-1) signaling is a central regulator for protein metabolism and maintenance of normal muscle mass,[13,15] and key molecules of this signaling pathway are also important in aging skeletal muscles. Aging is closely related to a decrease in insulin sensitivity, which can impair IGF-1 activity. However, binding of muscle IGF-1 to the IGF-1 receptor through an intracellular signaling pathways involving tyrosine kinase activity may exerts an anti-apoptotic effect and reduce muscle atrophy via phosphatidylinositol 3-kinase (PI3K)-dependent Akt-dependent phosphoryla- tion.[16] Gait characteristics were also changed in aged mice. Compared to young mice ( 3 months old), aged mice (24 months old) exhibited significantly decreased cadence, increased stride-time variability, and altered footfall patterns.[17]

The aged-rat model also showed patterns of muscle decrease similar to those of an aged-mouse model. Old male Wistar Han rats (19 months old) decreased body weight by $1.8 \pm 0.9 \%$, lean body mass by $0.3 \pm 1.0 \%$, and fat mass by $13.0 \pm 3.0 \%$ for 4 weeks.[18] Because high calorie intake is known to accelerate the setup of sarcopenia, some studies gave a high-fat diet to animals.[19,20] When Sprague-Dawley rats were fed a high-fat diet at 6 months old, a loss of muscle cross-sectional area was observed in males at 16 months of age. But female rats were resistant to sarcopenia induced by a high-fat diet.[21] Hence males seem susceptible for lipotoxic properties, and gender difference should be considered in this condition. The loss of muscle mass in the rat fed a high-fat diet is not because of reduction of the Akt pathway or an upregulation of the ubiquitin proteasomal degradation of muscle protein, because of unchanged expression of the main ubiquitin ligases of 
muscle, muscle atrophy F-box (MAFbx) and muscle RINGfinger protein-1 (MuRF-1).[22]

\section{MUSCLE ATROPHY INDUCTION MODEL}

\section{Hindlimb unloading}

The rodent HU model was originally devised to investigate the astronauts' musculoskeletal response to weightlessness or low-gravity conditions and has since been widely used as a muscle-wasting model mimicking the condition of muscle-wasting disease, inactivity, bed rest, and immobilization (Table 2).[23] Since weightlessness has been predicted to yield deficits in the principal tissues needed for structure and movement on Earth, primarily muscle and bone, the National Aeronautics and Space Administration (NASA) Ames Research Center (ARC) set up the HU model to study the mechanisms, responses, and treatments for the adverse consequences of spaceflight in the mid-1970s. After inception of the HU model at NASA, many laboratories have used the $\mathrm{HU}$ model to simulate weightlessness and subsequently used it as a muscle-wasting model. Since the standard operating procedure for applying the HU model to young and adult rodents was updated and approved by the NASA ARC Institutional Animal Care and Use Committee on August 8, 2001, more than 1,500 papers have published data that used this model system.[24]

The primitive HU model tested in 1975 was very simple, but led to suggestions for modifications ultimately incorporated into succeeding designs. The first HU model described in a full-length paper in 1979 used a hexcelite back harness and a cantilevered rotating beam that allowed the head-down animal to move in a $360^{\circ}$ arc.[25] Data were compared with the weight and bone changes found in the Cosmos 782 and 936 biological satellites, and the author concluded that the changes of body weight, food consumption, and bone-formation rates in $\mathrm{HU}$ rats were very similar to spaceflight. So the HU model closely mimics results from rat and man exposed to near-weightlessness during orbital spaceflight and will allow preliminary answers to questions posed by spaceflight experiments.

Musacchia and colleagues used a modified first HU model.[26] In this model, they used a denim harness and a rotating beam that allowed the animal to move in a $140^{\circ}$ arc. Body weight and food consumption in the $\mathrm{HU}$ rats were significantly less than those of the control group, and the animals exhibited adrenal hypertrophy at the end of the 7-day experiment. The authors concluded that the muscle changes were similar to those found during spaceflight and recovery from spaceflight. To find out whether the cephalad fluid shift contributed to changes in metabolism, Deavers and colleagues included a horizontal control and found that the head-down position was required for the diuresis and natriuresis that occurred during HU.[27] Stump and colleague [28] modified the model to measure muscle changes and blood flow. Deavers et al. [27] and Bouzeghrane et al. [29] advocated for a horizontal control, particularly for studies investigating fluid shifts. Hargens and colleagues [30] addressed the importance of the unloading angle. They found that the angle of unloading determined the amount of weight supported by the forelimbs as well as the tension applied to the tail, and showed that the HU rat applies $50 \%$ of its body weight to its forelimbs when the angle between the torso and the floor of the cage is $30^{\circ}$. As the angle increased, mechanical loading of the forelimbs declined and traction on the tail increased. If the angle was too steep, then the animals appeared stressed. A $30^{\circ}$ angle of unloading was recommended, because it provided normal weight bearing on the forelimbs, unloaded the lumbar vertebrae but not the cervical vertebrae,[31] and induced a cephalad fluid shift.[30]

The HU model has not changed conceptually from the beginning. Data from all laboratories that used the model showed differential muscle atrophy, a cephalad fluid shift, animals having the freedom to move, eat, and groom with the forelimbs, and unloading of the hindlimbs without paralysis so that animals could recover from unloading. However, the harness system and degree of mobility differed significantly between laboratories. One problem possibly related to these differences was the reduced weight gain in growing rats or weight loss in adult animals that persisted throughout the experimental period. Harnesses tested at ARC included a combination of elastic and Velcro straps and hexcelite bonded with an epoxy resin to the back of the rat.[25] Each of these harnesses was only partially successful, and less stressful harness designs were sought. The concept of a tail harness originated with our Russian colleagues, who used a plaster of Paris mold for tail traction. In the early 1980s, orthopedic surgeons from the University of Southern California toured our laboratory and recommended that the tail cast be replaced with the tape that 
they used for placing human limbs in traction. Traction tape could be applied to an unanesthetized animal and would allow the tail to grow without restriction. In fact, the body weights of growing rats unloaded with the use of tail traction remained comparable to those of controls fed the same amount of food (i.e., group-mean-fed controls), in contrast to rats unloaded with the use of back harnesses. Tail traction appears to be less stressful to animals than are whole-body harnesses, as assessed by corticosterone levels and adrenal, thymus, and body weights.[32]

Unlike other rat models, the $\mathrm{HU}$ model did not require confinement of animals in small cages, limb casting, or flaccid paralysis by nerve section or surgical tenotomy. None of these techniques produced the differential muscle atrophy characteristic of spaceflight, i.e., a decreased in mass of the extensor muscles but not of other muscles associated with movement. In addition, recovery from disuse was difficult or impossible with the existing surgical models. But the many studies that used the HU model clearly showed that independent variables can influence results obtained and, ultimately, the analog's validity in terms of understanding the mechanisms and physiological responses to spaceflight. Additional HU variables known to influence experimental results include age (growing vs. adult), sex, species (rat vs. mouse), and strain.

Chronic hindlimb suspension (HS) (unweighting) has been shown to limit growth and result in significant losses in hindlimb muscle mass, slow-twitch properties, and show myosin content.[33-37] This loss in muscle mass is more extensive in those muscles predominantly composed of slow-twitch (type I) fibers.[33,35,36,38] Although weightbearing activity (mechanical stress) appears to be a primary factor in maintaining muscle weight in the context of $\mathrm{HS}$,[37] evidence is lacking as to whether anabolic steroid treatment can serve as an independent stimulus to preserve muscle weight in the absence of weight-bearing activity.

\section{Denervation model}

It is thought that complex degeneration of the neuromuscular system contributes to dynapenia.[2,39-42] Neuromuscular changes contributing to myofiber denervation occur within the central and peripheral nervous systems as well as within skeletal muscle tissue. Changes include diminished function or loss of neurons in the brain and spi- nal cord, demyelination of nerves, and progressive degeneration of NMJs.[43,44] Skeletal muscle denervation, caused by such problems as traumatic peripheral nerve injury, disease, pharmacologic intervention, and aging (Table 3), diminishes the function leads to immediate muscle atrophy. $[14,45,46]$ Early muscle atrophy could be restored by a timely and appropriate reinnervation occurrence, but without one, myofiber atrophy progresses to irreversible changes in the muscle with muscle fibrosis and myofiber death.[47, 48] Denervation is a common phenomenon in an aged NMJ. The tibial- or sciatic-nerve transection model to induce the denervation is commonly employed and a wellvalidated model in rodents. Only a single dose of analgesic is necessary in the immediate postoperative period. With the use of proper sterile technique, soft-tissue infection is rare.[49] This model allows the investigator to use genetically engineered mice to study the process of muscle atrophy in vivo in the absence of proteins crucial to the regulation of muscle mass.[50,51]

The tibial-nerve transection model is a validated, reproducible, and well-tolerated model of denervation-induced skeletal muscle atrophy in rodents, and is used to study the physiologic, cellular, and molecular biologic mechanisms that underlie muscle atrophy in vivo in the gastrocnemius and soleus muscle. The tibial nerve is a mixed motor-sensory peripheral nerve in the rodent hindlimb and is 1 of the 3-terminal branches of the sciatic nerve. Transection of the tibial nerve denervates the gastrocnemius, soleus, and plantaris muscles (and the 3 small deep flexor muscles of the foot, including the tibialis posterior, flexor digitorum longus, and flexor hallicus longus), and is a wellstandardized and validated model in rats.[52,53] Also, various knockout (KO) and transgenic ( $\mathrm{Tg}$ ) mice allow us to assess the specific functions of proteins in the induction, development, and maintenance, or alternatively the resolution of muscle atrophy and fibrosis in vivo in this model. The tibial nerve supplies the gastrocnemius, soleus, and plantaris muscles, so its transection permits the study of denervated skeletal muscle composed of fast twitch (type II) fibers and/or slow twitch (type I) fibers. The gastrocnemius muscle is a mixed-fiber muscle (type I and type II, although predominantly type II), and the soleus muscle is composed of a large proportion of type I fibers, thereby providing both fast- and slow-twitch muscles for assessment.[54,55] The tibial-nerve transection model is suitable 


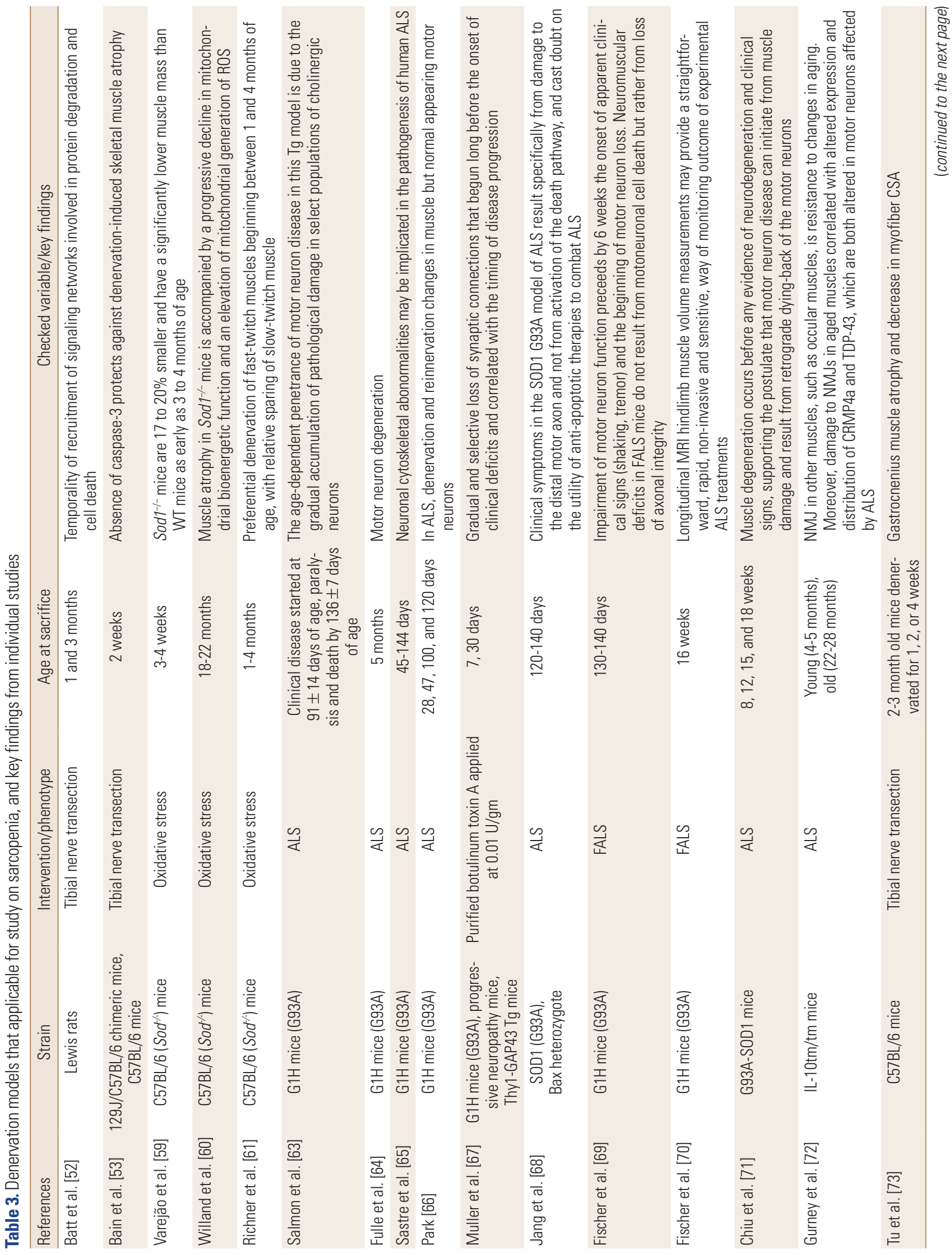




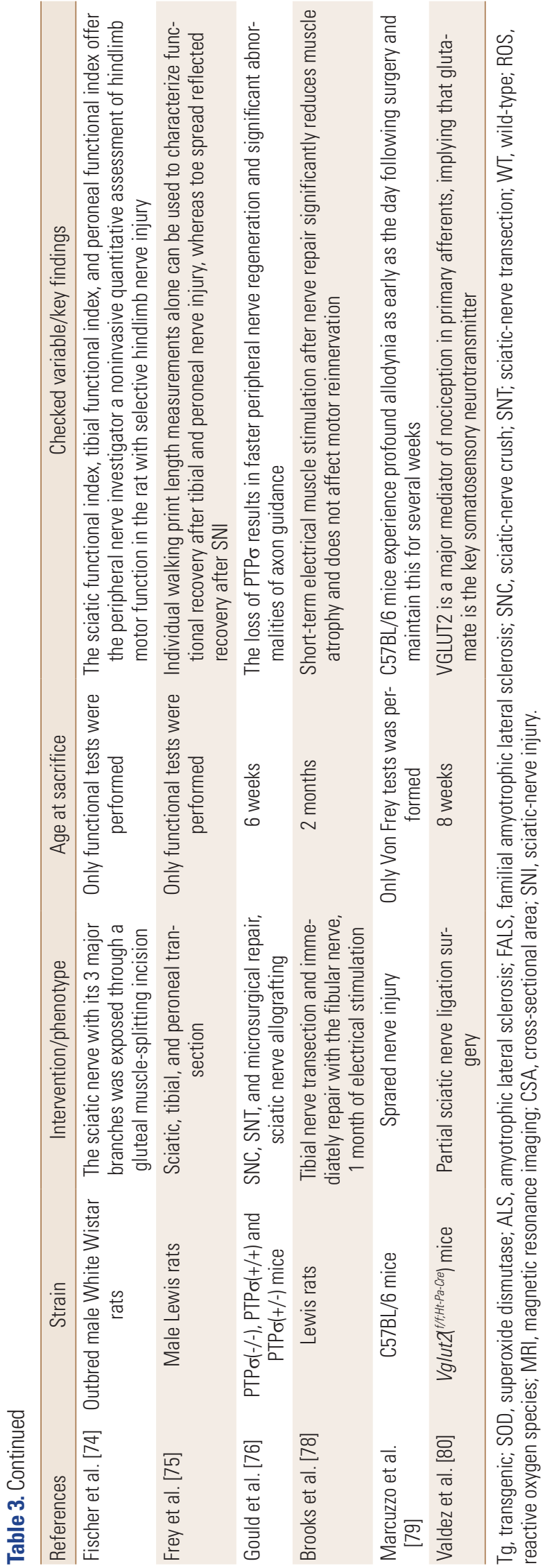

for studying the process of denervation-induced muscle atrophy in both the short term (days) [50] and long term (weeks to months).[51,52]

The gastrocnemius and soles muscles, both deserved in denervation model, can be easily and rapidly dissected with minimal handling, thus providing excellent-quality mRNA and protein for subsequent molecular analyses. Similarly, because of the size of the muscles, they can be split, providing tissue from the same animal for concomitant histologic and morphometric analyses. If hindlimb functional assessment is required, walking-track analysis can be serially done. The feet are dipped in ink, and the mouse is walked through an enclosure with paper on the bottom. Characteristics of the prints can be reliably measured and scored to indicate the extent of neuromuscular disability and gait compromise, since footprint characteristics reflect the functional muscle groups.[56,57] Although originally developed and validated in rats,[56] walkingtrack analysis can also be used with mice.[58]

The tibial nerve of only one hindlimb is transected, and since mice bear weight almost equally on both hindlimbs, the musculature from the contralateral un-operated limb can be used as an internal control within each animal.[50, $51,59,60]$ This is not necessarily the case in the sciatic transection model, where more significant abnormalities of gait can induce a hypertrophic response in the contralateral limb muscle. In the tibial-nerve transection model, we typically use the gastrocnemius and soleus muscle from the un-operated limb as our control muscle. [50,51] If the investigator chooses to use separate animals from which to harvest control muscle, then sham surgery should be performed. Sham surgery would consist of the administration of anesthesia, splitting of the skin to expose the tibial nerve, but no transection. The skin would simply be closed following nerve exposure.

Although tibial-nerve transection does induce sensory paraesthesia on the plantar aspect of the foot, the mice must be inspected daily for signs of auto-mutilation, heel pressure ulcers, or point-of-care endpoints. Although we have negligible mortality with the model, we find that approximately $2 \%$ to $5 \%$ of mice must be euthanized because of self-inflicted injury to, or pressure ulcers developing on, the operated hind limb. Sciatic-nerve ligation as well as the spared nerve injury model of ligation (where the tibial and common peroneal branches of the sciatic are 
ligated, but the sural is left intact) serve as models of neuropathic pain. $[61,62]$ Thus, allodynia and thermal hyperalgesia could occur in the foot in our model as well, but we have not seen overt pain behavior in the mice with normal daily activity on soft bedding.

One of the leading theories on mechanisms underlying age-related muscle denervation points to oxidative stress. [63-65] Reactive oxygen species (ROS) are natural byproducts of mitochondrial activity involved in respiration and energy production. ROS-mediated oxidative damages to DNAs, proteins, and lipids are normally kept in check by antioxidants. However, excessive ROS production can overwhelm the antioxidant defense, leading to increased oxidative damage of cellular machinery. Two mouse models, one lacking the $\mathrm{Cu} / \mathrm{Zn}$ superoxide dismutase (Sod1) gene and another harboring the Tg mutant human SOD1 gene, display progressive changes at the NMJ, including muscleendplate fragmentation, nerve-terminal sprouting, and denervation. These changes at the NMJ share many of the common features observed in the NMJs of aged mice.[66] SOD1 is a cytoplasmic antioxidant enzyme involved in the scavenging of superoxide free radicals. Mice lacking the SOD1 enzyme (Sod 1 1 mice) show increased oxidative damages to proteins, lipids, and DNAs.[67] In addition, these mice display progressive muscle denervation, weakness, and loss, changes seen despite the absence of a spinal cord motor neuron and ventral root axon loss.[68-70] NMJ denervation and sprouting are observed in these mice at between one and 4 months of age and precede muscle loss, $[69,70]$ which is observed at between 3 and 4 months of age.[67] Furthermore, muscle denervation and loss are greater in the gastrocnemius and tibialis anterior compared to the soleus. $[67,69,70]$ The G93A SOD1 mouse line Tg for SOD1 containing a point mutation at amino acid position 93 (G -> A) present in patients with familial amyotrophic lateral sclerosis. G93A SOD1 mice recapitulate many of the pathological hallmarks of amyotrophic lateral sclerosis, such as progressive muscle weakness and denervation, motor neuron loss, and paralysis.[71-73] It has been demonstrated that muscle denervation is observed as early as at 47 days of age in these mice [74-77] and precedes both motor neuron loss, $[62,63]$ and muscle atrophy. $[78,79]$ These characteristics are similar to those observed in the rodent models of aging $[14,80]$ as well as in Sod $1^{-1-}$ mice. $[69,70]$

\section{Immobilization}

Immobilization-induced skeletal muscle atrophy is characterized by a decrease in muscle mass and an increase in the risk of debilitating diseases and orthopedic problems (Table 4). The cast immobilization is the most frequently used model for studying muscle atrophy because it simulates conditions after fractures that require casts and wrap the leg with a plaster bandage or spiral wire; so this model can mimic prolonged immobilization.[12] The cast immobilization model may prove useful in studies on therapeutic interventions of muscle atrophy using $\mathrm{Tg}$ and mutant mouse strains.[81] This model could also evaluate the muscle loss, because muscles that are fixed in a contracted state show greater atrophy than do stretched muscle.[82] However, this model is time consuming, needs some skill, and may cause adverse events, including skin injury, local edema or necrosis, probably because of the retention of urine by the cast, and problems of escaping from the cast; so it requires experience, frequent observation, and replacement.[83-85] There are several methods for construction of a cast immobilization model. The traditional method is using the plaster cast on a unilateral or bilateral hindlimb. [86-91] After anesthesia, one or both hindlimbs was immobilized with a plaster cast and monitored on a daily basis for chewed plaster cast, abrasions, and problems with ambulation. Some modified methods have also been developed. Onda and colleagues used steel bonsai wire, which enables repeated direct access to the immobilized muscle and allows concurrent application and assessment of various therapeutic interventions.[92] In this study, the weight of the soleus and planters muscles were decreased significantly in both bilateral and unilateral immobilization and the mRNA expression of Fbxo32 (MAFbx [also known as atropin-1] protein coding gene) and Trim63 (MuRF1 protein coding gene) were also decreased in both muscles.[92] Another group developed a Velcro immobilization method using the commercially available hook-and-loop fastener that is faster and has less adverse events than does cast immobilization. They insist that Velcro immobilization could substitute for cast immobilization and allow the immobilization-intervention process to be repeated easily.[85] Speecht and colleagues explored disuse-induced muscle atrophy by using a unilateral casting model in conjunction with HS. They showed in the study that a 2-week HS resulted in a significant decrease in gastrocnemius and quadriceps 


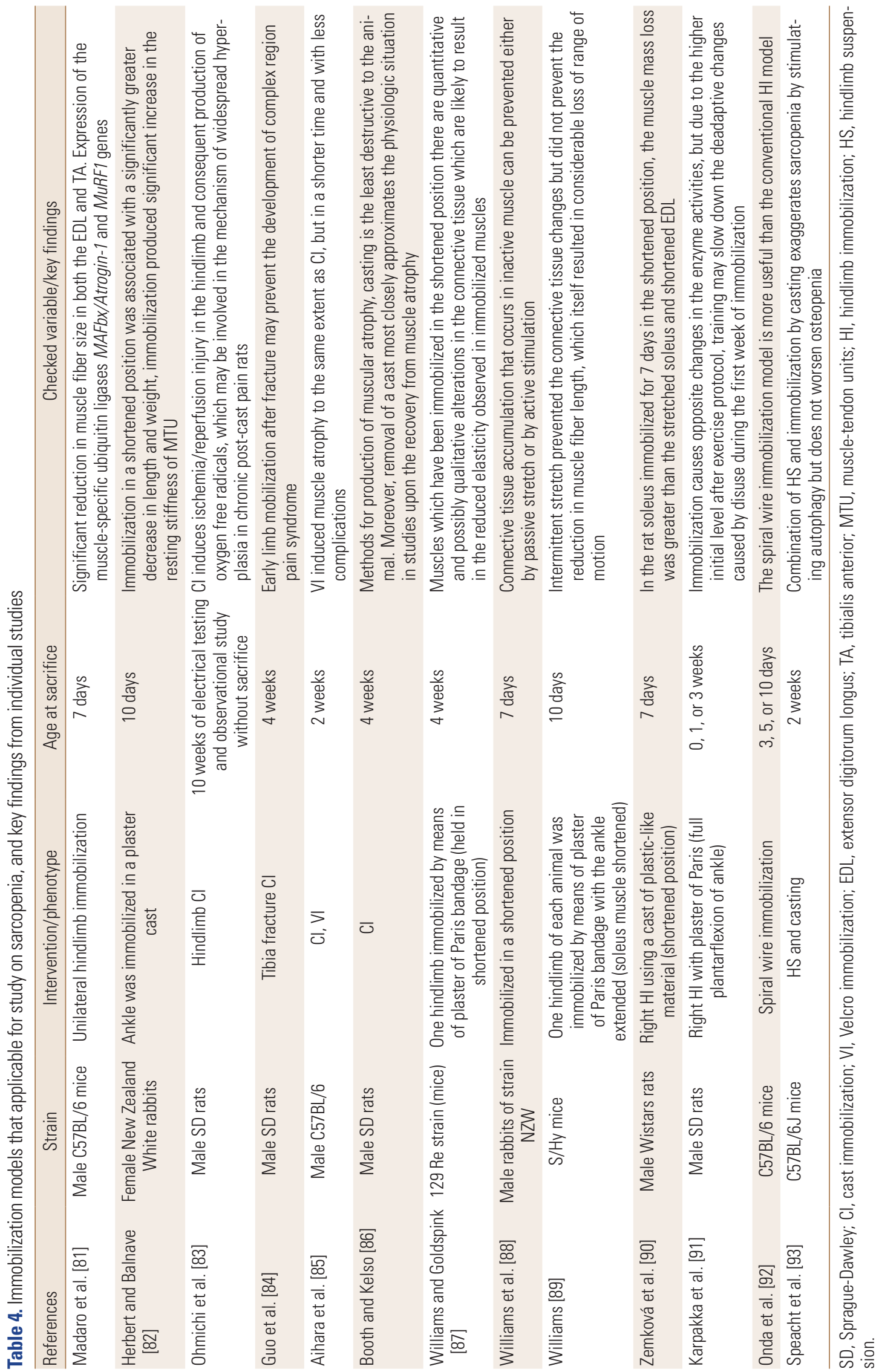


weight of about $9 \%$ to $10 \%$, but over a 2 -fold greater decrease in HS with casted limb.[93]

\section{CONSIDERATION FOR USING MOUSE MODEL IN THE STUDIES OF SARCOPENIA}

The mouse is a good animal model for studying the sarcopenia because of low cost, short life span, and relative ease of genetic manipulation.[94,95] Moreover, there are many previous studies shown similarities in aging processes between human and mouse.[96-98] But, of course, there are also significant differences between humans and mice, and this could be a limitation for specific applications. Mice exhibit higher regenerative capacities, their muscle mass only minimally declines with age, mice have high telomerase activity in many organs, and they can synthesize vitamin C.[99] Moreover, mouse breeding technology allows researchers to reduce biological variation as a source of experimental noise and also allows the exploitation of strain and cohort differences as a tool in aging research.[100]

The composition of the skeletal muscle fiber also differs between humans and mice. There are 2 types of skeletal muscle fiber (myofiber): type I is slow myofiber that have a slow contraction time and rely on oxidative phosphorylation pathways and resist fatigue. In contrast, type II is quick myofiber that have a fast contraction time and rely on glycolytic pathways and fatigue more easily. Human muscles are composed predominantly of type I myofibers, while mice are mainly type II: such differences between species need to be considered when extending observation from animal models to humans. Furthermore, there is more time for more secondary consequences to become pronounced in humans where sarcopenia becomes progressively manifest over 20 to 30 years, whereas the duration is far shorter in mice; $>1$ year (18-30 months), with the normal lifespan of mice being a mere 3 years or less. Innervation of myofiber is clearly required for skeletal muscle contraction in mice and humans, but different conclusions may be reached from initial studies.[101] Examination of aged mice (up to 29 months old) revealed marked denervation of NMJs of hind limb muscles without any change in number or size of motor neuron cell bodies in the lumbar spinal cord, suggesting a primary problem at the level of the muscles per se.[102] In contrast, many changes in motor neuron function are noted from electrophysiologi- cal studies in aging humans supporting changes in the central nervous system,[103] although it is difficult to determine whether these changes are secondary to earlier NMJ changes, since invasive examination of the NMJ status is rare in human studies. Further experiments in animal models can help to define the precise timing of these key events.

Although there are sarcopenia or senescence-accelerated rodent models with aging-related metabolic diseases which were generated by genetic modification, the models of muscular atrophy introduced in this study are relatively easy to apply for the experiments due to its time efficiency to obtain. Genetic modification models take long time and high cost to breed. Nevertheless, aging model still would be the most recommendable choice for the sarcopenia study among all the muscular atrophy models because the 'sarcopenia' means the 'aging-related muscular atrophy'. Therefore, when judged comprehensively, selecting an animal with an extreme-value after evaluating skeletal muscle mass and grip strength, etc. in aging rodents is probably the most appropriate method in sarcopenia research.

As mentioned above, using the aging rodent in the dictionary sense of the word "sarcopenia" may be the most desirable, but there is always a different perspective. In a variety of studies dealing with sarcopenia, muscular atrophy is also an important part of studying biological and molecular mechanisms, so choosing an aging rodent may not be the best option. Therefore, what is ultimately important is to rationally choose the animal model appropriate for research purpose.

\section{DECLARATIONS}

\section{Acknowledgments}

This work was supported by the National Research Foundation of Korea (NRF) grant funded by the Korea government (MEST) (No. NRF-2019R1F1A1059208).

\section{Conflict of interest}

No potential conflict of interest relevant to this article was reported.

\section{ORCID}

Kyung-Wan Baek https://orcid.org/0000-0002-8445-3773 
Youn-Kwan Jung https://orcid.org/0000-0002-5784-6221

Jin Sung Park

https://orcid.org/0000-0002-6284-9566

Young-Sool Hah https://orcid.org/0000-0002-8571-2722

Jun-II Yoo

https://orcid.org/0000-0002-3575-4123

\section{REFERENCES}

1. Rosenberg IH. Summary comments. Am J Clin Nutr 1989; 50:1231-3.

2. Janssen I. Evolution of sarcopenia research. Appl Physiol Nutr Metab 2010;35:707-12.

3. Lloyd N. AIM coalition announces establishment of ICD10 -CM code for sarcopenia by the centers for disease control and prevention. 2016 [cited by 2016 Apr 28]. Available from: https://www.aginginmotion.org/news/2388-2/

4. Melton LJ 3rd, Khosla S, Crowson CS, et al. Epidemiology of sarcopenia. J Am Geriatr Soc 2000;48:625-30.

5. Abellan van Kan G. Epidemiology and consequences of sarcopenia. J Nutr Health Aging 2009;13:708-12.

6. Dennis RA, Przybyla B, Gurley C, et al. Aging alters gene expression of growth and remodeling factors in human skeletal muscle both at rest and in response to acute resistance exercise. Physiol Genomics 2008;32:393-400.

7. Eley HL, Russell ST, Tisdale MJ. Effect of branched-chain amino acids on muscle atrophy in cancer cachexia. Biochem J 2007;407:113-20.

8. Deuster PA, Morrison SD, Ahrens RA. Endurance exercise modifies cachexia of tumor growth in rats. Med Sci Sports Exerc 1985; 17:385-92.

9. Lorite MJ, Smith HJ, Arnold JA, et al. Activation of ATPubiquitin-dependent proteolysis in skeletal muscle in vivo and murine myoblasts in vitro by a proteolysis-inducing factor (PIF). Br J Cancer 2001;85:297-302.

10. Adams V, Nehrhoff B, Späte U, et al. Induction of iNOS expression in skeletal muscle by IL-1 beta and NFkappaB activation: an in vitro and in vivo study. Cardiovasc Res 2002;54:95-104.

11. Schindler R, Mancilla J, Endres S, et al. Correlations and interactions in the production of interleukin-6 (IL-6), IL1 , and tumor necrosis factor (TNF) in human blood mononuclear cells: IL-6 suppresses IL-1 and TNF. Blood 1990; 75:40-7.

12. Palus S, Springer Jl, Doehner W, et al. Models of sarcopenia: Short review. Int J Cardiol 2017;238:19-21.

13. Shavlakadze T, Grounds M. Of bears, frogs, meat, mice and men: complexity of factors affecting skeletal muscle mass and fat. Bioessays 2006;28:994-1009.

14. Chai RJ, Vukovic J, Dunlop S, et al. Striking denervation of neuromuscular junctions without lumbar motoneuron loss in geriatric mouse muscle. PLoS One 2011;6:e28090.

15. Schiaffino S, Mammucari C. Regulation of skeletal muscle growth by the IGF1-Akt/PKB pathway: insights from genetic models. Skelet Muscle 2011;1:4.

16. Giovannini S, Marzetti E, Borst SE, et al. Modulation of GH/IGF-1 axis: potential strategies to counteract sarcopenia in older adults. Mech Ageing Dev 2008;129:593601.

17. Tarantini S, Yabluchanskiy A, Fülöp GA, et al. Age-related alterations in gait function in freely moving male $\mathrm{C} 57 \mathrm{BL} / 6$ mice: Translational relevance of decreased cadence and increased gait variability. J Gerontol A Biol Sci Med Sci 2019;74:1417-21.

18. Pötsch MS, Tschirner A, Palus S, et al. The anabolic catabolic transforming agent (ACTA) espindolol increases muscle mass and decreases fat mass in old rats. J Cachexia Sarcopenia Muscle 2014;5:149-58.

19. Fellner C, Schick F, Kob R, et al. Diet-induced and age-related changes in the quadriceps muscle: MRI and MRS in a rat model of sarcopenia. Gerontology 2014;60:530-8.

20. Bollheimer LC, Buettner R, Pongratz G, et al. Sarcopenia in the aging high-fat fed rat: a pilot study for modeling sarcopenic obesity in rodents. Biogerontology 2012;13: 609-20.

21. Kob R, Fellner C, Bertsch T, et al. Gender-specific differences in the development of sarcopenia in the rodent model of the ageing high-fat rat. J Cachexia Sarcopenia Muscle 2015;6:181-91.

22. Brown JC, Harhay MO, Harhay MN. Sarcopenia and mortality among a population-based sample of communitydwelling older adults. J Cachexia Sarcopenia Muscle 2016; 7:290-8

23. Lawler JM, Song W, Demaree SR. Hindlimb unloading increases oxidative stress and disrupts antioxidant capacity in skeletal muscle. Free Radic Biol Med 2003;35:9-16.

24. Morey-Holton ER, Globus RK. Hindlimb unloading rodent model: technical aspects. J Appl Physiol (1985) 2002;92: 1367-77.

25. Morey ER. Spaceflight and bone turnover: Correlation with a new rat model of weightlessness. Bioscience 1979; 29:168-72. 
26. Musacchia XJ, Deavers DR, Meininger GA, et al. A model for hypokinesia: effects on muscle atrophy in the rat. J Appl Physiol Respir Environ Exerc Physiol 1980;48:47986.

27. Deavers DR, Musacchia XJ, Meininger GA. Model for antiorthostatic hypokinesia: head-down tilt effects on water and salt excretion. J Appl Physiol Respir Environ Exerc Physiol 1980;49:576-82.

28. Stump CS, Overton JM, Tipton CM. Influence of single hindlimb support during simulated weightlessness in the rat. J Appl Physiol (1985) 1990;68:627-34.

29. Bouzeghrane F, Fagette S, Somody L, et al. Restraint vs. hindlimb suspension on fluid and electrolyte balance in rats. J Appl Physiol (1985) 1996;80:1993-2001.

30. Hargens AR, Tipton CM. Tissue fluid shift, forelimb loading, and tail tension in tail-suspended rats. Physiologist 1984;27:S37-8.

31. Globus RK, Bikle DD, Morey-Holton E. The temporal response of bone to unloading. Endocrinology 1986;118: 733-42.

32. Halloran BP, Bikle DD, Cone CM, et al. Glucocorticoids and inhibition of bone formation induced by skeletal unloading. Am J Physiol 1988;255:E875-9.

33. Fell RD, Gladden LB, Steffen JM, et al. Fatigue and contraction of slow and fast muscles in hypokinetic/hypodynamic rats. J Appl Physiol (1985) 1985;58:65-9.

34. Fitts RH, Metzger JM, Riley DA, et al. Models of disuse: a comparison of hindlimb suspension and immobilization. J Appl Physiol (1985) 1986;60:1946-53.

35. Jaspers SR, Tischler ME. Atrophy and growth failure of rat hindlimb muscles in tail-cast suspension. J Appl Physiol Respir Environ Exerc Physiol 1984;57:1472-9.

36. Templeton GH, Padalino M, Manton J, et al. Influence of suspension hypokinesia on rat soleus muscle. J Appl Physiol Respir Environ Exerc Physiol 1984;56:278-86.

37. Tsika RW, Herrick RE, Baldwin KM. Interaction of compensatory overload and hindlimb suspension on myosin isoform expression. J Appl Physiol (1985) 1987;62:2180-6.

38. Goldspink DF, Morton AJ, Loughna $P$, et al. The effect of hypokinesia and hypodynamia on protein turnover and the growth of four skeletal muscles of the rat. Pflugers Arch 1986;407:333-40.

39. Ryall JG, Schertzer JD, Lynch GS. Cellular and molecular mechanisms underlying age-related skeletal muscle wasting and weakness. Biogerontology 2008;9:213-28.
40. Thompson LV. Age-related muscle dysfunction. Exp Gerontol 2009;44:106-11.

41. Delbono O. Neural control of aging skeletal muscle. Aging Cell 2003;2:21-9.

42. Rosenberg IH. Sarcopenia: origins and clinical relevance. J Nutr 1997;127:990s-1s.

43. Luff AR. Age-associated changes in the innervation of muscle fibers and changes in the mechanical properties of motor units. Ann NY Acad Sci 1998;854:92-101.

44. Flood DG, Coleman PD. Neuron numbers and sizes in aging brain: comparisons of human, monkey, and rodent data. Neurobiol Aging 1988;9:453-63.

45. Valdez G, Tapia JC, Kang H, et al. Attenuation of age-related changes in mouse neuromuscular synapses by caloric restriction and exercise. Proc Natl Acad Sci U S A 2010;107:14863-8.

46. Yang F, Wang W, Li J, et al. Antler development was inhibited or stimulated by cryosurgery to periosteum or skin in a central antlerogenic region respectively. J Exp Zool B Mol Dev Evol 2011;316:359-70.

47. Fu SY, Gordon T. Contributing factors to poor functional recovery after delayed nerve repair: prolonged denervation. J Neurosci 1995;15:3886-95.

48. Kobayashi J, Mackinnon SE, Watanabe O, et al. The effect of duration of muscle denervation on functional recovery in the rat model. Muscle Nerve 1997;20:858-66.

49. Batt JA, Bain JR. Tibial nerve transection - a standardized model for denervation-induced skeletal muscle atrophy in mice. J Vis Exp 2013:e50657.

50. Nagpal P, Plant PJ, Correa J, et al. The ubiquitin ligase Nedd4-1 participates in denervation-induced skeletal muscle atrophy in mice. PLoS One 2012;7:e46427.

51. Plant PJ, Bain JR, Correa JE, et al. Absence of caspase-3 protects against denervation-induced skeletal muscle atrophy. J Appl Physiol (1985) 2009;107:224-34.

52. Batt J, Bain J, Goncalves J, et al. Differential gene expression profiling of short and long term denervated muscle. FASEB J 2006;20:115-7.

53. Bain JR, Veltri KL, Chamberlain D, et al. Improved functional recovery of denervated skeletal muscle after temporary sensory nerve innervation. Neuroscience 2001; 103:503-10.

54. Sher J, Cardasis C. Skeletal muscle fiber types in the adult mouse. Acta Neurol Scand 1976;54:45-56.

55. Agbulut $O$, Noirez $P$, Beaumont $F$, et al. Myosin heavy chain 
isoforms in postnatal muscle development of mice. Biol Cell 2003;95:399-406.

56. Bain JR, Mackinnon SE, Hunter DA. Functional evaluation of complete sciatic, peroneal, and posterior tibial nerve lesions in the rat. Plast Reconstr Surg 1989;83:12938.

57. Hare GM, Evans PJ, Mackinnon SE, et al. Walking track analysis: utilization of individual footprint parameters. Ann Plast Surg 1993;30:147-53.

58. McLean J, Batt J, Doering LC, et al. Enhanced rate of nerve regeneration and directional errors after sciatic nerve injury in receptor protein tyrosine phosphatase sigma knock-out mice. J Neurosci 2002;22:5481-91.

59. Varejão AS, Meek MF, Ferreira AJ, et al. Functional evaluation of peripheral nerve regeneration in the rat: walking track analysis. J Neurosci Methods 2001;108:1-9.

60. Willand MP, Holmes M, Bain JR, et al. Electrical muscle stimulation after immediate nerve repair reduces muscle atrophy without affecting reinnervation. Muscle Nerve 2013;48:219-25.

61. Richner M, Bjerrum OJ, Nykjaer A, et al. The spared nerve injury (SNI) model of induced mechanical allodynia in mice. J Vis Exp 2011;54:3092.

62. Rogoz K, Lagerström MC, Dufour S, et al. VGLUT2-dependent glutamatergic transmission in primary afferents is required for intact nociception in both acute and persistent pain modalities. Pain 2012;153:1525-36.

63. Salmon AB, Richardson A, Pérez VI. Update on the oxidative stress theory of aging: does oxidative stress play a role in aging or healthy aging? Free Radic Biol Med 2010; 48:642-55.

64. Fulle S, Protasi F, Di Tano G, et al. The contribution of reactive oxygen species to sarcopenia and muscle ageing Exp Gerontol 2004;39:17-24.

65. Sastre J, Pallardó FV, Viña J. The role of mitochondrial oxidative stress in aging. Free Radic Biol Med 2003;35:1-8.

66. Park KH. Mechanisms of muscle denervation in aging: insights from a mouse model of amyotrophic lateral sclerosis. Aging Dis 2015;6:380-9.

67. Muller FL, Song W, Liu Y, et al. Absence of CuZn superoxide dismutase leads to elevated oxidative stress and acceleration of age-dependent skeletal muscle atrophy. Free Radic Biol Med 2006;40:1993-2004.

68. Jang YC, Lustgarten MS, Liu Y, et al. Increased superoxide in vivo accelerates age-associated muscle atrophy through mitochondrial dysfunction and neuromuscular junction degeneration. FASEB J 2010;24:1376-90.

69. Fischer LR, Li Y, Asress SA, et al. Absence of SOD1 leads to oxidative stress in peripheral nerve and causes a progressive distal motor axonopathy. Exp Neurol 2012;233: 163-71.

70. Fischer LR, Igoudjil A, Magrané J, et al. SOD1 targeted to the mitochondrial intermembrane space prevents motor neuropathy in the Sod1 knockout mouse. Brain 2011; 134:196-209.

71. Chiu AY, Zhai P, Dal Canto MC, et al. Age-dependent penetrance of disease in a transgenic mouse model of familial amyotrophic lateral sclerosis. Mol Cell Neurosci 1995; 6:349-62.

72. Gurney ME, Pu H, Chiu AY, et al. Motor neuron degeneration in mice that express a human $\mathrm{Cu}, \mathrm{Zn}$ superoxide dismutase mutation. Science 1994;264:1772-5.

73. Tu PH, Raju P, Robinson KA, et al. Transgenic mice carrying a human mutant superoxide dismutase transgene develop neuronal cytoskeletal pathology resembling human amyotrophic lateral sclerosis lesions. Proc Natl Acad Sci U S A 1996;93:3155-60.

74. Fischer LR, Culver DG, Tennant P, et al. Amyotrophic lateral sclerosis is a distal axonopathy: evidence in mice and man. Exp Neurol 2004;185:232-40.

75. Frey D, Schneider C, Xu L, et al. Early and selective loss of neuromuscular synapse subtypes with low sprouting competence in motoneuron diseases. J Neurosci 2000; 20:2534-42.

76. Gould TW, Buss RR, Vinsant S, et al. Complete dissociation of motor neuron death from motor dysfunction by Bax deletion in a mouse model of ALS. J Neurosci 2006; 26:8774-86.

77. Kennel PF, Finiels F, Revah F, et al. Neuromuscular function impairment is not caused by motor neurone loss in FALS mice: an electromyographic study. Neuroreport 1996;7:1427-31.

78. Brooks KJ, Hill MD, Hockings PD, et al. MRI detects early hindlimb muscle atrophy in Gly93Ala superoxide dismutase -1 (G93A SOD1) transgenic mice, an animal model of familial amyotrophic lateral sclerosis. NMR Biomed 2004; $17: 28-32$

79. Marcuzzo S, Zucca I, Mastropietro A, et al. Hind limb muscle atrophy precedes cerebral neuronal degeneration in G93A-SOD1 mouse model of amyotrophic lateral sclero- 
sis: a longitudinal MRI study. Exp Neurol 2011;231:30-7.

80. Valdez G, Tapia JC, Lichtman JW, et al. Shared resistance to aging and ALS in neuromuscular junctions of specific muscles. PLoS One 2012;7:e34640.

81. Madaro L, Smeriglio P, Molinaro M, et al. Unilateral immobilization: a simple model of limb atrophy in mice. Basic Appl Myol 2008;18:149-53.

82. Herbert RD, Balnave RJ. The effect of position of immobilisation on resting length, resting stiffness, and weight of the soleus muscle of the rabbit. J Orthop Res 1993; 11:358-66.

83. Ohmichi Y, Sato J, Ohmichi M, et al. Two-week cast immobilization induced chronic widespread hyperalgesia in rats. Eur J Pain 2012;16:338-48.

84. Guo TZ, Wei T, Li WW, et al. Immobilization contributes to exaggerated neuropeptide signaling, inflammatory changes, and nociceptive sensitization after fracture in rats. J Pain 2014;15:1033-45.

85. Aihara M, Hirose N, Katsuta W, et al. A new model of skeletal muscle atrophy induced by immobilization using a hook-and-loop fastener in mice. J Phys Ther Sci 2017;29: 1779-83.

86. Booth FW, Kelso JR. Production of rat muscle atrophy by cast fixation. J Appl Physiol 1973;34:404-6.

87. Williams PE, Goldspink G. Connective tissue changes in immobilised muscle. J Anat 1984;138:343-50.

88. Williams PE, Catanese T, Lucey EG, et al. The importance of stretch and contractile activity in the prevention of connective tissue accumulation in muscle. J Anat 1988; 158:109-14.

89. Williams PE. Effect of intermittent stretch on immobilised muscle. Ann Rheum Dis 1988;47:1014-6.

90. Zemková H, Teisinger J, Almon RR, et al. Immobilization atrophy and membrane properties in rat skeletal muscle fibres. Pflugers Arch 1990;416:126-9.

91. Karpakka J, Väänänen K, Orava S, et al. The effects of preimmobilization training and immobilization on collagen synthesis in rat skeletal muscle. Int J Sports Med 1990; 11:484-8.

92. Onda A, Kono H, Jiao Q, et al. New mouse model of skel- etal muscle atrophy using spiral wire immobilization. Muscle Nerve 2016;54:788-91.

93. Speacht TL, Krause AR, Steiner JL, et al. Combination of hindlimb suspension and immobilization by casting exaggerates sarcopenia by stimulating autophagy but does not worsen osteopenia. Bone 2018;110:29-37.

94. Yuan R, Peters LL, Paigen B. Mice as a mammalian model for research on the genetics of aging. ILAR J 2011;52:4-15.

95. Yuan R, Tsaih SW, Petkova SB, et al. Aging in inbred strains of mice: study design and interim report on median lifespans and circulating IGF1 levels. Aging Cell 2009;8:27787.

96. Barreto G, Huang TT, Giffard RG. Age-related defects in sensorimotor activity, spatial learning, and memory in C57BL/6 mice. J Neurosurg Anesthesiol 2010;22:214-9.

97. Graber TG, Ferguson-Stegall L, Kim JH, et al. C57BL/6 neuromuscular healthspan scoring system. J Gerontol A Biol Sci Med Sci 2013;68:1326-36.

98. Parks RJ, Fares E, Macdonald JK, et al. A procedure for creating a frailty index based on deficit accumulation in aging mice. J Gerontol A Biol Sci Med Sci 2012;67:21727.

99. Vanhooren $\mathrm{V}$, Libert $\mathrm{C}$. The mouse as a model organism in aging research: usefulness, pitfalls and possibilities. Ageing Res Rev 2013;12:8-21.

100. Miwa S, Jow H, Baty K, et al. Low abundance of the matrix arm of complex I in mitochondria predicts longevity in mice. Nat Commun 2014;5:3837.

101. Sayer AA, Robinson SM, Patel HP, et al. New horizons in the pathogenesis, diagnosis and management of sarcopenia. Age Ageing 2013;42:145-50.

102. Shavlakadze T, McGeachie J, Grounds MD. Delayed but excellent myogenic stem cell response of regenerating geriatric skeletal muscles in mice. Biogerontology 2010; 11:363-76.

103. Aagaard $P$, Suetta $C$, Caserotti $P$, et al. Role of the nervous system in sarcopenia and muscle atrophy with aging: strength training as a countermeasure. Scand J Med Sci Sports 2010;20:49-64. 